\title{
Separating hype from reality in the era of the affordable genome
}

$\mathrm{E}$ arly adopters of new technologies often pay more than people willing to wait for prices to drop, but few have seen the cost of their purchase plummet like Dan Stoicescu. In 2008, Stoicescu, a successful biotechnology entrepreneur, became the second person to purchase his entire genetic sequence. Price tag: US\$350 000. Just four years later, the price of full-genome sequencing is quickly approaching US\$1000. Ouch. One can only hope Stoicescu wasn't pressured into also buying the extended warranty.

Though the fast-falling price of fullgenome sequencing may be inducing buyer remorse in a few millionaires, it is good news for everybody else. "As it gets less and less costly, genomic information will become much more accessible," says Cinnamon Bloss, lead investigator of the Scripps Genomics Health Initiative at the Scripps Translational Science Institute in La Jolla, California.

So the era of the affordable genome is nearly upon us, which means, surely, we are finally on the cusp of the muchanticipated age of personalized medicine, when drugs will be tailored to everybody's unique biochemistry, when the mysteries of disease will be laid bare, when trial and error in medical treatment will become but a memory, when health care will be individualized, revolutionized and super-duperized.

Cue sound of trumpets. Health care heaven is imminent.

Well, that might be overstating things a tad. Separating hype from reality in the field of genomic medicine isn't easy. For more than a decade, many lofty promises about the potential of genetics to improve human health have been made but, in general, humans aren't getting any healthier. Turns out a genetic test for predisposition to obesity doesn't make jogging more fun or cheesecake less delicious.

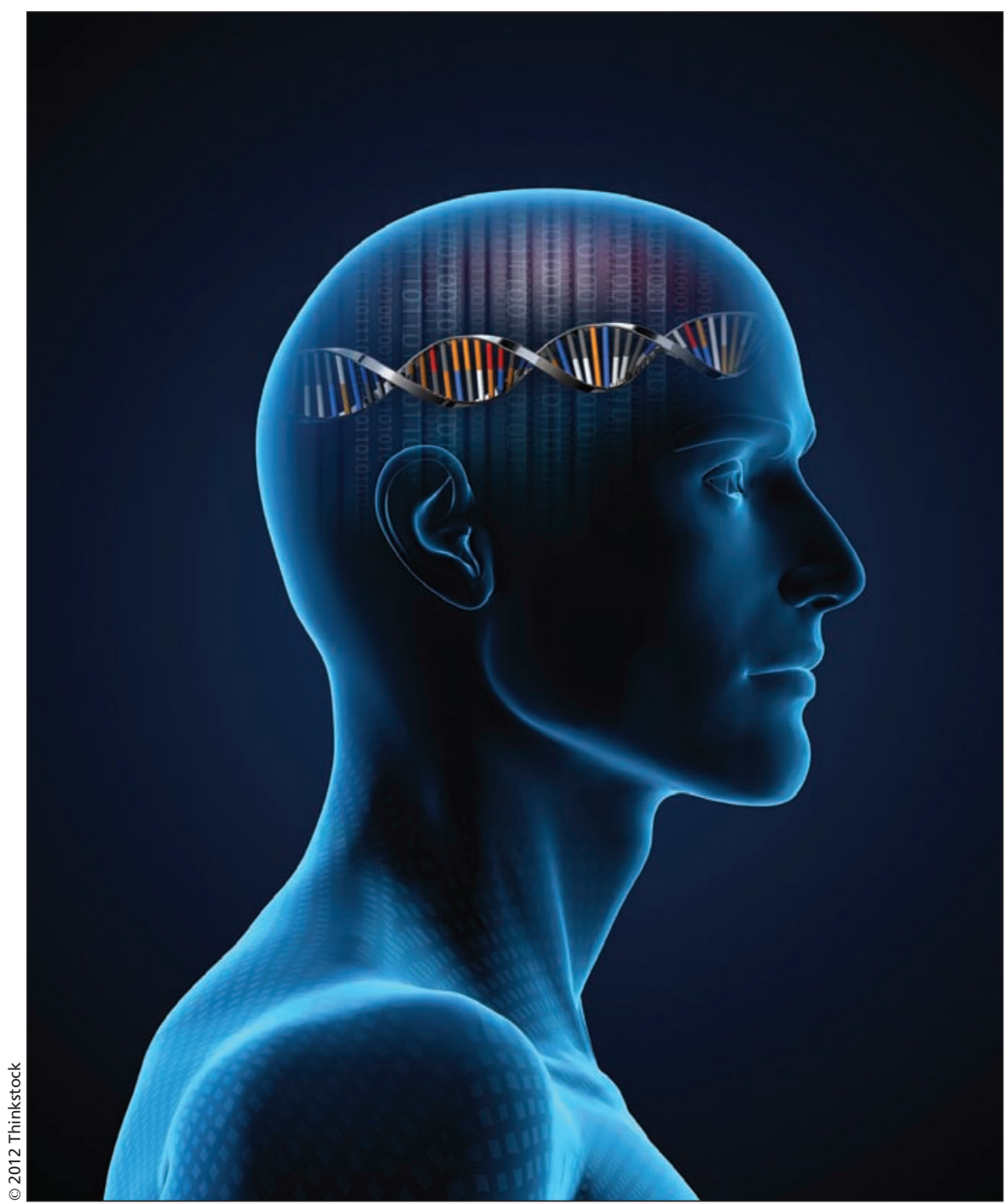

The era of the affordable genome provokes as many philosophic and therapeutic issues as it resolves.

That doesn't mean, of course, that genomic medicine is a bust. Far from it, say genetic researchers. There is plenty of promising work being conducted in labs, some of it ready to be integrated into clinical care. But will this research lead to a revolution in medicine? Probably not. A more realistic view is that genetic technologies will become valuable, not transformative, tools in the fight against disease.

"Like any new technology, you get a big rush of enthusiasm and then you get a backlash," says Dr. James Evans, editor-in-chief of Genetics in Medicine and Bryson Distinguished Professor of Genetics and Medicine at the University of North Carolina in Chapel Hill. "The reality is somewhere in between."

$C M A J$ will be exploring that inbetween reality in a series of articles, touching on various philosophic and therapeutic issues related to genetic medicine, including: 
Hype: The excitement surrounding genomic medicine started as genuine enthusiasm among researchers but quickly ballooned into exaggerated expectations and predictions of a revolution in medicine. How did that happen? What can researchers learn from it? Will the inevitable backlash tarnish the field of genetics?

Paternalism: In the early days of direct-to-consumer genetic testing, many geneticists suggested that consumers shouldn't interpret genetic information alone, but rather should consult with physicians. Actually, many still feel that way. What if patients discover devastating news? Does that cause anxiety? Advocates for access to personal genetic information say people can handle the truth and that physicians, though well intentioned, need to stop worrying so much.

Race-based medicine: It's well known that certain diseases are more prevalent in particular ethnic groups. Does that mean race is a good proxy for genetic ancestry? Many genetic experts say it isn't. Fearing that companies might exploit race to market new health products, they warn against creating therapies for specific races. Furthermore, they suggest, focusing on genetics rather than on social and economic inequalities might actually increase the health disparities among different ethnic groups.

Family medicine: Many experts in genetics are wary of direct-to-consumer genetic testing and are calling for regulations to ensure physicians are involved in the process. But how do family doctors, who may not have expertise in genetics, feel about that? Are they ready and able to discuss the benefits and risks of genetic testing with their patients?

Predictive: The marketing departments of direct-to-consumer genetic testing companies make some bold claims about the predictive value of their services. But can the test actually uncover health risks? Some genetic experts are skeptical and consider such endeavours little more than recreational genetics.

Behaviour: Information is power, so the cliché goes. But does genetic information have the power to change unhealthy behaviours? If not, can it somehow be leveraged to help people put down doughnuts and pick up dumbbells?

Prophylactic surgery: As more and more people dig into their genomes and discover predispositions toward diseases such as cancer, will there be an increase in people undergoing preventive surgery? How, for example, do doctors feel about removing healthy breasts and ovaries from a 30-year-old woman?

Insurance: Despite laws in some countries to ward off genetic discrimination, some people still fear the secrets in their genes will be used against them. Will health insurers in the United States, for instance, eventually base premiums on genomes? What about long-term health insurance or disability insurance? On the flip side, is it fair for people with knowledge of predispositions to disease to load up on insurance? Will the model used by the insurance industry have to change? Roger Collier, CMAJ

CMAJ 2012. DOI:10.1503/cmaj.109-4143

Editor's note:

First of a multipart series on genetic testing.

Next: Popping the genetics bubble (www.cmaj.ca/lookup/doi/10.1503 /cmaj.109-4142). 